\title{
REAL-LIFE LEARNING: WHY, WHAT AND HOW?
}

\author{
Keynote address to IFIP ICT and RLL working conference
}

Peter Juliff

Emeritus Professor, School of Information Systems, Deakin University, Australia

\begin{abstract}
This paper presents a personal perspective on the evolution of ICT education at university level in Australia. It focuses on the development of IT courses in Institutes of Technology, which had a real-life orientation and recruited their academic staff with this in mind. Issues relating to real-life learning are discussed with a warning on the need for vigilance against over-stressing the benefits of 'real-world' as opposed to 'mere theory'. The paper approaches this discussion by considering issues under the headings: why, what and how.
\end{abstract}

Key words: Vocational/ professional education, real-life learning, Institutes of Technology.

\section{INTRODUCTION}

I was pleased to be asked to make the keynote presentation for this conference. Its theme of Real-life Learning has been one of the major concerns during my own academic career over a period of approximately forty years. I came to academia after ten years spent in public administration, by which time I had been appointed to a position of Public Service Inspector (EDP) in the state of Victoria. This was in the mid-60s when commercial computer-based systems were in their infancy and computing education was an emerging discipline. Like others of my kind, I had no academic computing qualifications and was recruited because of my "real-life" experience. From then it has been a continual scramble to keep up with advances in technology, advances in the nature of ICT education, advances in ICT practices and the growth of the ICT profession. 
The progress of my working career reflects the progress of ICT education in this country:

- 1956-67: Employed by the Victorian Public Service, commencing in the Office of the Government Statist and Actuary using the electromechanical calculating devices of the time, ending in the EDP Inspectorate overseeing the introduction of the first administrative computing systems in the Public Service and completing an Associate Diploma in EDP (Accounting) at Caulfield Technical College - then part of the Technical Division of the Victorian Education Department.

- 1967 - 78: Appointed as a Teacher at Caulfield Technical College, re-classified as a Lecturer in the re-named Caulfield Institute of Technology on the formation of the Victoria Institute of Colleges in 1969. During this time I graduated in the first cohort of the Bachelor of Applied Science (Computing) awarded as a result of the general upgrading of Institutes' qualifications from Diplomas.

- 1978-79: Deputy Programming Manager, Health Computing Services of Victoria on the campus of Monash University - an escape from academia back to "real life".

- 1980-89: Head of EDP Department, Prahran College of Advanced Education, re-named Victoria College on amalgamation with two Teachers' Colleges in the first series of institutional amalgamations in 1982.

- 1990-92: Head of Department of Software Development, Chisholm Institute of Technology (the re-named Caulfield Institute of Technology) and amalgamated in 1990 with Monash University, becoming part of the Faculty of Computing and Information Technology in a second series of institutional amalgamations.

- 1993-98: Professor and Foundation Chair of the School of Management Information Systems, Deakin University, by then incorporating the former Victoria College as a result of the same amalgamations which saw the Chisholm/Monash merger.

So, as can be seen, most of my time in academia has been spent in Institutions of Technology where the commitment to real-life learning was an essential part of the culture. During that time, I have maintained an ongoing association with the ICT industry and have been involved in the design and implementation of a wide variety of commercial computer-based systems. These started with applications written in assembler for a Burroughs B400 (because it had 400 memory locations) keying in the code via an accounting machine keyboard and processing data on punched paper tape, through numerous systems on Honeywell, ICL, Burroughs and Control Data hardware programmed in COBOL and updating magnetic tape master 
files with transactions recorded on punched cards to PC-based applications written in Visual Basic maintaining relational databases.

It is this experience I would like to draw upon in this address.

\section{SOME GENERAL HISTORY}

- Until around 15 years ago, Australia had a binary system of tertiary education. Go back another 15 years before that and there was also a binary system of secondary education. In both cases, the binary division was broadly on the basis of "vocational" vs. "academic" studies.

- At secondary level, students were often separated into a vocational or an academic stream after the second year of secondary education (Year 8, in current parlance), i.e. at about age thirteen. The vocational stream essentially meant training for a trade and often led to an apprenticeship. It was not impossible for a student in this stream to move across to the academic stream but it was not regarded as a common occurrence.

- Secondary students completing the academic stream after Year 12 then had a further choice if they wanted to pursue tertiary education. There were the Institutes of Technology, or Colleges of Advanced Education as some were named, and there were the Universities. Until the mid-1970s, the awards from the Institutes were designated as Diplomas and those from the Universities as Degrees. Institutes/Colleges offered courses mainly in Business Studies, Public Administration, Teaching and Engineering. Graduates were recognised as having practical skills and knowledge enabling them to fit into a working environment and become productive in a minimal time. Universities offered the traditional disciplines of Arts, Commerce, Law, Medicine, Science, Engineering, etc. Graduates were generally regarded as being well versed in the theory of their discipline and having acquired the ability to conduct research enabling them to extend that body of knowledge but not necessarily having much in the way of practical experience.

- Recruitment of staff by the various institutions reflected the differences in the perceived requirements of their students. Academic staff in the Institutes were often chosen on the basis of their practical knowledge and experience and were expected to have or to acquire teaching qualifications the better to be able to impart their skills to their students. University academics were usually chosen on the basis of their achievements as students and their ability to conduct research in their chosen discipline. They were not 
expected to have nor to pursue any particular skill in teaching, the implication presumably being that students would acquire the knowledge of their lecturers by an osmotic process.

- In the late 1980s, the then Labor government engineered the mergers of the Institutes and Colleges with existing Universities or, in very few cases, their conversion to university nomenclature. This was ostensibly in the interest of homogenising tertiary education and thus providing all students with the dual benefits of vocational/practical education and a scholarship/research culture. Thereby, in a single stroke, they extinguished the benefits of both branches of tertiary education. This was coupled with an exhortation from the Treasury for universities to go forth and multiply their enrolments of overseas, fee-paying students and the subsequent embarrassing touting for students which has seen universities indulging in a scramble for enrolments and, arguably, compromising their standards in terms of entry requirements and course criteria.

- The role of TAFE (Technical and Further Education) Colleges has expanded to absorb much of the vacuum left by the demise of the Institutes of Technology. Their Diploma courses have been standardised across the country to remove the idiosyncrasies of individual institutions' delivery and some courses now lead to Degree awards.

- It is interesting that, after 30 years, it was one of the planks in the Liberal Party's recent re-election platform to re-introduce vocational senior high schools for students not aspiring to the heights of the university system which has long since been tuned down to accommodate those entering from the single high school stream no longer given the choice of tertiary study at an Institute of Technology.

\section{SOME HISTORY OF ICT EDUCATION, IN PARTICULAR}

- Against the above background, we can trace the evolution of ICT education in Australia. In the late 1950s and early 60s, Australian universities began to acquire computing equipment. This was the province of Science departments and was available to a small number of science/mathematics students for whom the computer represented an advance on the electro-mechanical computation equipment then available. This expanded over the years to form the computer science curricula typical in most of the world's universities. The emphasis was on the electronics of the computer's 
operations and the production of software such as operating systems and compilers. Programming was typically done at an assembler or machine language level, or using a home-developed higher-level language or, in due course, proprietary languages such as Fortran, Algol, Pascal or C. There was little attempt made to orient course material towards the burgeoning commercial computing/data processing market or to use software common in that environment. Systems analysis and design, for example, was nowhere to be found among university curricula, the conventional wisdom of the time being that this was impossible to impart to undergraduate students.

- ICT education in the Institutes of Technology, on the other hand, was almost entirely commercially oriented. The early courses were a mixture of Diplomas in Electronic Data Processing (as it was then termed) for school leavers and the pre-cursors of today's Graduate Diplomas for professionals in the workplace wishing to understand, and take advantage of, the emerging technology. The interesting factor about the school leavers enrolling for Diploma courses was that many of them came not from the academic high school stream but from the technical/vocational stream. These were students who originally opted, or had their choice made for them by their parents or teachers, not to eventually pursue an academic tertiary education. Their technical high school education, however, had inspired them to aim beyond a manual trade and the newly emerging data processing technology appealed to them as a hands-on, rather than a book-learning, activity. In this state of Victoria, vocational ICT education stemmed entirely from the area of technical high school education. The curricula typically embraced the three areas of equipment, programming and systems analysis and design. The early equipment curricula used to embrace also the areas of accounting machines and punched card systems which existed in parallel with early computer systems.

- In the tradition of the Institutes of Technology, teaching staff were recruited on the basis of their knowledge and experience in the ICT marketplace. This became evident in curricula developed and nature of practical work undertaken by students. The aim of the courses was, as it had always been, to produce graduates with the skills and knowledge to be immediately productive in a working environment.

- By way of rounding off the picture, in the early 1980s computer science subjects began to be introduced into the final year of high school curricula in the teeth of opposition from the university Computer Science academics who initially refused to count marks obtained in this subject towards a student's university entrance criteria. 


\section{REAL-LIFE LEARNING}

- We in this Working Group are proponents of vocational and professional education in information technology. It is therefore natural to expect us to raise the banner of Real-life Learning. It begs two questions, however: What is "real" about the Real-life; and, what is "learned" in the education process?

- Whose reality do we teach to our students? At first blush, it is attractive for a lecturer to be able to say to a group of students, "This is the way we did things where I worked". Even more attractive, of course, to say "This is the way we do things where I work." This is real-life experience. But, wait a moment: is the way they do, or did, things at the lecturer's workplace the correct or best way to do them? Is the lecturer merely delivering a history lesson? Is the lecturer reinforcing a less-than-perfect (this could be a euphemism for justplain-wrong) set of practices? So, what do the students learn? Do they learn only one way to approach a particular problem because it is the only way the lecturer has ever known? I worked with an academic whose burning desire was to write the definitive work on the sorting of magnetic tape files. This was long after the world had moved on to disk storage. However, he would deliver his standard lecture on the intricacies of pre-stringing and multiple passes because he "knew" that this was the stuff of real-life systems.

- It is necessary to be eternally vigilant to avoid over-stressing the benefits of the "real world" as opposed to "mere theory". Indeed, in a nutshell, this had been a perennial bone of contention between Institute and University academics. Skills may be acquired more readily than knowledge, and practice based only on skill without an understanding of the underlying theory has a very limited usefulness.

\section{WHY?}

- The values of real-life learning are numerous:

- It illustrates practical implementation of theory. The world of ICT is one of solving problems. A theory must be able to be implemented to be of use in the marketplace. A real-life example is an excellent way to demonstrate usefulness.

- It provides motivation. Which of us has not had a student ask "Do we really need to know this stuff you're teaching us?" If we can lead the student to a working example of the application of "this stuff", the question is already answered. 
- It builds confidence in the student. Faced with a problem in a working situation, the graduate is better equipped to solve it if he or she has seen or, better still, done something similar before.

- There is a basic assumption here which comes from my own background of over 25 years in Institutes of Technology: that is, we are preparing students to become productive contributors to the ICT marketplace. For the vast majority of my own academic career, the main criterion on which I judged the success or otherwise of my courses and teaching efforts, and the efforts of my staff, was whether or not my graduates were able to gain employment as ICT practitioners. My last 10 years spent in the University system has, of course, required me to re-evaluate that criterion. University education has never been primarily about graduates being employable at its conclusion. Such an outcome might be considered by some to be a serendipitous by-product of graduation but surely not the guiding principle for academics and course developers. Given the propensity for universities to hire graduates as tutors while they pursue research for higher qualifications and then to appoint them as lecturers until they have served on enough committees to become heads of departments, what could be more "real-life" for an aspiring academic than sitting in a class room?

\section{WHAT?}

- The most obvious "what" is the work itself. ICT is essentially a practical profession. It is about getting things done and, usually, done in a hurry. Requirements of ICT systems are constantly evolving. The largest problem of the dinosaur systems in the past was not that they didn't do a job but that the job was outdated by the time they did it. The tools currently available for rapid system development enable and encourage evolutionary system design. Students often enter the workforce not merely without an understanding of the realities of ICT system development but without an understanding of the realities of the working environment both internal and external to their place of employment. A large slab of this "real-life" component is indeed - real LIFE. Students need to be aware of the realities and restrictions involved in systems interacting with others of their species.

- Why can we not achieve our goal by providing students with realistic assignment work during their course? Do we need to push them out of the nest to do this? The answer to that lies in the 
difference between systems in the large and systems in the small. By necessity, student assignments must be devised so as to be realistically possible of solution within the duration of their parent academic subject; i.e. one semester of around 10 to 13 weeks. Some of even this short time must be devoted to the learning of whatever skill level is needed to commence the assignment. Academics are aware that their unit is only one of many being undertaken concurrently by their students and assignments from one unit must not monopolise the students' time. So, we devise systems in the small. The problem is hopefully representative of a working situation but of such a small scale as to remove many of the problems which size alone brings.

Size may be manifested in many ways:

- Allowing concurrent access to system resources by $\mathrm{N}$ users;

- Maintenance of fast access to $\mathrm{N}$ entities in a database;

- Development of software by $\mathrm{N}$ parallel programmers;

- Writing a program of $\mathrm{N}$ lines of code;

- Satisfying the requirements of $\mathrm{N}$ users of a system;

- Maintaining acceptable service levels over a network of $\mathrm{N}$ nodes.

All of the above are likely to increase by an exponential rather than a linear function of $\mathrm{N}$.

Real-life exposure can give students a feeling for systems in the large. Only by seeing the difference which this makes to the process of system development and operation can the gulf between a student assignment and a working project be appreciated. I have often advocated the criterion of a professional programmer being able to produce 1,000 lines of debugged code per day. Many students would not produce 1,000 lines of debugged code in the entirety of their course.

- Another "what" to be learned is the difficulty which most working professionals have in keeping up with their profession. Students come to the workforce after three or four years of having had the luxury of being able to increase their knowledge base. Indeed, they are rewarded for doing so; in addition, they are force-fed by their lecturers. It may come as a complete surprise to them that their newly-found workmates do not have the time or, in many cases, the funds to enrol in enrichment courses just for the sake of learning something new. It may also be a surprise to the graduates that their employer is not prepared to reward them for efforts expended in keeping abreast of technology which is not immediately relevant to their current work. 
- I would like to think that a further benefit of exposing students to real-life learning would be the gaining of experience in professional ethics and codes of practice. It has been my experience that undergraduate students have polarised attitudes to the issue of ethical behaviour among practitioners of a profession. Some will learn the code promulgated by their local professional body and merely regurgitate the chapter and verse which they perceive applicable to a posed question. Others will cynically adopt an attitude that you do whatever you can get away with without being caught. Graduates working in ICT should be prepared to evaluate their chosen vocation to reach a conclusion as to whether it really is a profession. Students with a cavalier attitude to matters of ethics in an ICT context are often horrified when asked if they would be happy for their lawyer, tax accountant or doctor to adopt the same approach to the privacy of data.

The lack of espousal of a truly professional code of ethics and public practice has been the largest factor in the reluctance of the community to accept ICT as a true profession.

\section{HOW?}

- The real-life component of learning may be imparted internally or externally. Internal embedding of such concepts may be reflected in the nature of the course material presented to students and the assignments required to be undertaken. The problems related particularly to assignments were discussed earlier. One means of injecting reality into course content is the use of real-life software and hardware in the students' education. The early days of ICT education often saw educational institutions using home-developed programming languages in lieu of those used at the time in industry. It is interesting to note that, in this category, a distinctly nonacademic language - Basic - has survived to become one of today's cornerstones while a much more academic example - Pascal - was never accepted outside academia. A further example of this dichotomy was the widespread popularity of COBOL in the commercial marketplace because of its ability to get a job done. Given that getting a job done was never a criterion of the average academic, the language was generally regarded as beneath a computer science academic's dignity to include in course material. The principle of exposing students to real-life software applies also to the use of proprietary products such as Windows and its related 
companions for text processing, data storage and manipulation, spreadsheets and presentation media.

- An approach taken by some universities, not without its critics, is that of building a whole course, or a substantial part thereof, around a particular workplace product or qualification. Many courses are built around enterprise-wide products such as SAP. Technology courses often incorporate training to enable graduates to acquire an industry qualification such as Microsoft's MCSE or Novell's CNE. The benefits to graduates are obvious: a ready-made entry into a corner of the marketplace. The danger, of course, is the possibility that "education" is replaced by "training".

- The internal imparting of a real-life flavour to course material relies on the developers and presenters of the material having some reallife to impart. The binary system of Institutes of Technology and Universities, as already discussed, encouraged the employment of practitioners with real-life experience in the Institutes while not providing the same encouragement for University staff. However, the propensity for many of the Institute practitioners to become "snap-frozen" upon employment meant that both arms of the education process were faced with the same problem: how do you keep the experience of your staff current?

One approach to solving this has been to release staff into the general workforce periodically: the concept of sabbatical or industrial leave. In a currently under-staffed environment such as tertiary education has become, the problem is: how to you manage to release staff for prolonged periods? And, in a traditionally highlypaid and manpower-hungry profession such as ICT has usually been, the problem is: can you be sure that they will return?

- External real-life learning for undergraduates has traditionally been accomplished by sandwich courses. Students are released into the workforce, usually with one further year of study still to complete, to work in a full-time industry environment for which they are paid a normal rate of salary. While this may seem ideal for the student, the realities for the educational institution are extremely demanding. The finding of industry sponsors, continued mentoring of students by liaison with nominated academics and the associated administration are a heavy burden on the university. It is not uncommon to find that this organisation requires the full-time attention of one member of academic staff. Students' experiences are also often mixed in terms of perceived benefits. Some employers are reluctant to commit the resources needed within their own organisation to make the students' work experience meaningful and professionally rewarding. 
- One of the significant areas of distinction between Institutes and Universities was the Course Advisory Committee. Institutes of Technology would invariably have such a committee composed of representatives from industry, the relevant professional body and sister Institutes to review course structure and content. This was done with the express purpose of ensuring that courses had a reallife basis in terms of the need for graduates of the type intended to be produced and the knowledge and skills to be acquired in the course. With the abolition of this arm of education went the existence of the committee. Universities obviously have no need for such input. They are fiercely committed to self-governance. Yet another opportunity for some real-life to be injected into our learning is extinguished. To be fair, it must also be admitted that some industry-based members of such committees were equally inclined to dismiss as irrelevant any course material not seen as directly leading to a workplace skill.

- Some of the institutions at which I have worked have had active student associations which have organised guest speakers from industry to make periodic presentations on matters of real-life interest. This enables students to obtain a feel for the issues which are felt to be important in the marketplace and also, embarrassingly on occasions, to invite the speakers' comments on the material which the students are currently being taught. In the absence of this initiative on the part of the students themselves, the academic staff have sometimes attempted to organise this facility for the students. This has inevitably resulted in failure due to terminal apathy on the part of the students and embarrassingly low attendances at the speakers' presentations.

\section{CONCLUSION}

- There is enough of the educational dinosaur in me to make me feel that real-life learning is valuable.

- For students to see it as valuable, staff must be able to present such experience with confidence and conviction.

- For staff to be able to do that, they must be at least aware of what real-life entails even if they have had no such experience themselves.

- Professional bodies such as the Australian Computer Society devote considerable effort to organising activities aimed at maintaining the level of relevance of their members and members of the profession in general. University staff have 
traditionally ignored both the professional bodies and their activities.

- Students of ICT disciplines have traditionally had little difficulty in obtaining well-paid employment upon graduation and have had an expectation of life-long employment without much more effort on their part in terms of continuing education. That is no longer the case.

- Academics in ICT disciplines have traditionally had little difficulty in attracting students into their courses because the courses were seen as leading to certain employment. Because the latter is no longer the case, neither is the former. Most ICT faculties have recently been involved in significant down-sizing.

- Fewer ICT jobs for graduates may have the effect of increasing the perceived value of having acquired some real-life learning along the way.

- The advisability of being able to provide such real-life learning in a course may convince academics that it is to be valued. Some may even be so bold as to take the next step and acquire it. 